\title{
Diferansiyel Denklemlerin Öğreniminde Yaşanan Zorluklar ve Alternatif Öğretim Yaklaşımları
}

\begin{abstract}
Eyüp SEVİMLí
Öz

Bu çalışma, yükseköğretim matematiğinin önemli ders ve alanlarından biri olan diferansiyel denklemler için eğitim alanında yapılan araştırmaların bir derlemesini içermektedir. Diferansiyel denklemler konusunda uluslararası alanda yapılan çok sayıda araştırma olmasına rağmen Türkçe eğitim literatüründeki çalışmaların sınırlı olması bir eksikliktir. Çalışma kapsamında, diferansiyel denklemler konusunun öğrenimi sürecinde öğrencilerin yaşadıkları zorluklar ve bu alanın öğretimi sürecinde kullanılabilecek alternatif yaklaşımlar değerlendirilmiştir. Diferansiyel denklemlerin öğrenimi ve öğretimi sürecinde karşılaşılan zorluklar dört başlık altında sunulmuştur. Bunlar; kavramsal anlama yerine işlemsel anlama, muhakeme zorluğu, kavram yanılgısı ve temsiller arası geçiş zorluğudur. Özellikle cebir temelli rutin hesap uygulamaları yerine diferansiyel denklemlerin nümerik ve geometrik anlamlarını açığa çıkaran sorgulayıcı ve teknoloji destekli yeni eğilimler paylaşılmıştır. Bu derleme çalışması, Türkçe literatüre yapacağı katkının yanı sıra; matematik eğitimi araştırmacıları için de bilgi ve farkındalık oluşturması nedeniyle önemlidir.
\end{abstract}

Anahtar Kelimeler: Diferansiyel Denklem, Öğrenme Zorluğu, Kavram Yanılgısı, Alternatif Yaklaşımlar.

\section{The Challenges Encountered in the Process of Learning the Differential Equations and Alternative Teaching}

\section{Approaches}

\begin{abstract}
This study contains a review of researches conducted in the area of education for differential equations, which is one of the important courses and fields of higher education in mathematics. Although there are so many researches done in the international literature on differential equations, it is a deficiency that there are limited researches in the Turkish educational literature. Challenges which students experience in the process of learning the subject of differential equations and alternative approaches to be used in the process of teaching have been analysed in this study. The challenges encountered in the process of learning and teaching of the differential equations can be collected under the four titles. These are procedural understanding instead of conceptual understanding, reasoning difficulties, misconception and transitional challenges between representations. Instead of algebra based routine calculation module, inquiry-based and technology-supported new tendencies which reveal the numerical and graphical meanings of the differential equations have
\end{abstract}

\footnotetext{
*Yrd. Doç. Dr., Gaziosmanpaşa Üniversitesi, eyup.sevimli@gop.edu.tr
} 
been shared. This review research is important because of that it contributes to the Turkish literature and also that it creates awareness of knowledge for researchers of mathematics education.

Keywords: Differential Equations, Learning Difficulties, Misconceptions, Alternative Approaches.

\section{GİRIŞ}

Fizik, mühendislik, astronomi, ekonomi ve istatistik gibi disiplinlerdeki gerçek hayat problemlerini ifade etmek üzere kullanılan matematiksel modellerde, genellikle çeşitli diferansiyel denklem türlerinden yararlanılır. Bu matematiksel modeller üretilirken birbirine bağlı olarak değişen büyüklükler (değişken) ve bir niceliğin diğer bir niceliğe göre değişim oranına (türev) ihtiyaç duyulur (Sezer ve Daşcıoğlu, 2010). Örneğin; Newton'un ikinci yasasında $F=m \cdot a$ formülü ile gösterilen ivme değişkeni, hızın zamana göre değişimi olarak yorumlandığında birinci mertebeden, mesafenin zaman göre değişimi olarak yorumlandığında ikinci mertebeden bir diferansiyel denklem elde edilir. Hem üstelik türevler arasındaki ilişkiyi diferansiyel denklem modelleri üzerinden çözmek ve günlük hayattaki karşılıklarını yorumlamak daha kolaydır. Yukarıdaki ifadelerden yola çıkarak diferansiyel denklemlerin bir veya birden çok değişken ve bu değişkenlerin türevi arasındaki bağıntıyı açıkladığını söyleyebiliriz.

Diferansiyel denklemler, yükseköğretim düzeyinde alınan bir ders veya matematiğin bir alanı olmakla birlikte, anlaşılması süreci, ileri matematiksel düşünme becerilerini gerektirir (Artigue, 1992; Dana-Picard ve Kidron, 2007; Rasmussen, 1997; Raychaudhuri, 2014). Her ne kadar diferansiyel denklemlerin günlük hayat problemleri çözümünde önemli ve kullanışlı olduğu belirtilse de, geleneksel öğretim ortamlarında bu düşünceyi destekleyen içerikler sınırlıdır (Kwon, Rasmussen ve Allen, 2005; Rasmussen, 2001). Çünkü günlük hayat içerisindeki problem durumlarını modelleyen birçok diferansiyel denklem türü için analitik çözümler mevcut değilken, klasik bir diferansiyel denklem dersinde genellikle analitik çözüm tekniklerinin kullanılabileceği (kapalı formlu ve sonlu çözümlü) içeriklere yer verilmektedir (Habre, 2000). Bilgi teknolojilerinin gelişmesi ile ortaya çıkan ihtiyaçlar ve geleneksel öğretim içeriği ile günlük hayat uygulamaları arasındaki zayıf ilişkiler, diferansiyel denklemler dersinde reform olarak nitelendirilebilecek yeni yaklaşımlarının araştırılmasına yol açmıştır. Özellikle son yirmi yılda yapılan eğitim araştırmalarında, diferansiyel denklemler dersinde kullanılan geleneksel öğretim içerik ve yaklaşımların sebep olduğu yanılgı ve zorluklar belirlenmiş; bunların giderilmesi için kullanılabilecek alternatif yaklaşımlar tartışılmaya başlanmıştır (Artigue, 1992; Buendia ve Cordero, 2013; Burtch, 2005; Camacho-Machín ve Guerrero, 2015; Kwon, 2009; Rasmussen, 1997). Diferansiyel denklemler dersinde güncel öğretim hedeflerine ulaşmak amacıyla yapılan yurtdışı ölçekli araştırmalar, Türkiye'de yeterince karşılık bulmamıştır. İlgili alanda yapılmış araştırmaları derleyen Türkçe yeterli kaynağın olmayışı, bu konunun Türkiye bağlamındaki yansımalarını sınırlamış olabilir. Bu anlamda yapılmış çalışmalardan birinde Arslan (2008), diferansiyel denklemlerin öğretiminde kullanılabilecek farklı yaklaşımları ve özel olarak nitel yaklaşımların gerekliliğini açıklamıştır. Öğrencilerin diferansiyel denklem konularında yaşadıkları yanılgı ve zorlukları uluslararası araştırmalar üzerinden derleyen Türkçe bir çalışmanın, yükseköğretim kademesinde görev yapan matematik eğitimcileri için de farkındalık oluşturacağı düşünülmektedir. Çalışma kapsamında öğrencilerin diferansiyel denklemlerin öğreniminde yaşadıkları yanılgı ve zorluklar belirlenmiş; ayrıca literatürde bu zorlukların giderilmesine yönelik kullanılması önerilen yaklaşımlar tartışılmıştır. 


\subsection{Diferansiyel Denklem Kavramı ve Tarih- sel Gelişimi}

Bir takım fonksiyonlar ve bunların türevleri arasındaki ilişkiyi konu alan diferansiyel denklemlerin ortaya çıkışı, türev kavramı ile benzerlik göstermektedir. Diferansiyel denklem kavramına ilişkin ilk çalışmalar, 17. yüzyılda, Isaac Newton (1642-1727) ve Gottfried Wilhelm Leibniz (1646-1716) tarafından "yerçekimine karşı vücudun hareketini" açıklamak amacıyla yapılmıştır (Upton, 2004). Daha sonraki zamanlarda Daniel Bernoulli (1700-1782), Leonhard Euler (1707-1783) ve Joseph-Louis Lagrange'ın (1736-1813) katkılarıyla akışkanlar mekaniğindeki problem durumlarını açıklamak için çeşitli diferansiyel denklem sistemleri ve hesap yöntemleri geliştirilmiştir. Bu sebeple fen bilimciler, diferansiyel denklemleri, fiziksel kural ve modellerin durumunu açıklayan bir dil olarak görmektedir (Keene, 2007). Bu kural ve modellere örnek olarak verilebilecek durumlar; radyoaktif bir maddenin parçalanması, sıvı yüzeyinde oluşan dalga hareketinin boyu, bir popülasyonun büyüme aritmetiği ve uçağın kalkış/denge durumunda gerekebilecek hava yakıtının kontrolünü sağlayacak aerodinamik karakterlerdir. Günümüzde gerçek hayat ile ilişkili sayısız problem için çözüm üreten diferansiyel denklemlerin ilk ortaya çıkış formu, birinci mertebeden diferansiyel denklemleri tanımlamak üzere $d y / d x=f(x, y)$ gösteriminin Newton tarafından 1690 yılında kullanması ile başlamıştır. Diferansiyel denklemlerin ilk ortaya çıktığı dönemde homojen ve değişkenlerine ayrılabilen adi diferansiyel denklemler üzerinde çalışılmış; 18. yüzyılda matematiğin fizikteki uygulama alanlarının gelişmesiyle birlikte lineer olmayan, birden çok çözümü olan kısmi diferansiyel denklem türleri için de hesap yöntemleri geliştirilmiştir.

Diferansiyel denklemlerin çözümünde üç tür hesap yöntemi göze çarpmaktadır Bunlar; cebirsel, geometrik ve sayısal hesap yöntemleridir (Hunt, Lardy, Lipsman, Osborn ve Rosenberg, 2009). Bu yöntemlerin kullanılması ile diferansiyel denklemlerin çözümlerinde kullanılabilecek farklı yaklaşımlar ise sırasıyla analitik, nitel ve nümerik yaklaşımlardır (Arslan, 2008; Habre, 2000; Rasmussen, 1997). 18. yüzyılın ortalarına kadar diferansiyel denklemlerin çözümü için kullanılan yegane yaklaşım analitik iken, diferansiyel denklemlerin büyük çoğunluğunda cebirsel hesap yöntemlerinin uygulanamıor olması, sayısal yöntemlerinin geliştirilmesine neden olmuştur. Diferansiyel denklemlerin karakteristik davranışlarının geometrik olarak yorumlanabilmesi yani topolojik olarak incelenmesine yönelik çalışmalara 20. yüzyılda başlanmıştır. Özellikle teknolojinin son 30 yıldaki gelişimine paralel olarak yüksek matematikte kullanılabilen bilgisayar destekli hesaplama araçlarının da gelişmesi, nitel ve nümerik yaklaşımlar ile diferansiyel denklemlerin daha detaylı analiz edilmesine imkân sağlamıştır. Bugün üniversite düzeyindeki matematik dersleri dizisi içerisinde yer alan diferansiyel denklemler, matematiğin uygulamalarını kullanan farklı programlar için bir ön gerekliliktir. Yükseköğretim matematiğindeki öğretim sırasına göre diferansiyel denklemler dersi, analiz ve lineer cebir derslerinden sonra verilmektedir. Çünkü diferansiyel denklemler dersindeki konuların anlaşılabilmesi için gerekli olan ön bilgiler, analiz ve lineer cebir dersinde işlenmektedir (Raychaudhuri, 2008). Matematik bölümü ile birlikte fizik ve mühendislik bölümü öğrencileri de öğrenim hayatlarının ilk yılında matematik analiz dersi, ikinci yılında ise Diferansiyel Denklemler dersi ile karşılaşır (Rasmussen, 2001). Geleneksel siniflardaki diferansiyel denklemler dersinde öğrencilerin, öğretim içeriği ve öğretim yöntemi kaynaklı bazı zorluklar yaşadıkları bilinmektedir (Allen, 2006; Artigue, 1992; Burtch, 2005; Donovan, 2002; Duvall, 2005; Habre, 2000; Rasmussen, 
1997; Zandieh ve McDonald, 1999). Bu anlamda diferansiyel denklemlerin öğrenimi ve öğretimi sürecinde öğrencilerin karşılaştıkları zorluklar ve bu zorlukların kaynaklarına ilişkin literatür taraması bir sonraki başlık altında derlenmiştir.

\section{DIFERANSIYYEL DENKLEMLERIN ÖĞRENIMINDE VE ÖĞRETIMINDE YAŞANAN ZORLUKLAR}

Diferansiyel denklemler dersinde, sonucu henüz kestirilemeyen problem durumlarına cevap aramak için fonksiyonların bir veya birden çok değişkene göre değişim oranları incelenir. $\mathrm{Bu}$ yönüyle diferansiyel denklem problemleri de tıpkı diğer matematiksel problem durumları gibi bir takım çözüm stratejilerinin belirlenmesi ve sistematik olarak uygulanması süreçlerini içerir. Üstelik diferansiyel denklem problemlerinin çözümünde, ileri matematiğin en çok zorluk yaşanan iki konusu olan türev ve integralin uygulamaları doğrudan kullanılır (Raychaudhuri, 2008). Bu durum, öğrencilerin diferansiyel denklem konularında bazı yanılgı ve zorluklar yaşamasına neden olmaktadır. Cornu (1991), öğrencilerin yaşadığı bilişsel zorlukların üç nedeninden söz ederken bunları epistemolojik, psikolojik ve pedagojiye yönelik zorluklar olarak sıralamaktadır (akt. Zembat, 2010). Epistemolojik zorluk, kavramın doğasını; psikolojik zorluk öğrenen bireyi; pedagojik zorluk ise öğrenme sürecini konu edinir. Diferansiyel denklemler dersinde bu üç tür zorluğun her biri için çeşitli örneklerle karşılaşmak mümkündür. Diferansiyel denklem ifadelerinde kullanılan notasyonların karmaşık yapısı, epistemolojik; bireyin muhakeme zorluğuna veya sınırlı kavram imajina sahip olması, psikolojik; kavramsal bilgi ve disiplinler arası ilişki gerektiren içeriklere öğretim sürecinde yeteri kadar yer verilmemesi, pedagoji kaynaklı zorlukların oluşmasına neden olabilir (Allen,
2006; Donovan, 2002; Rasmussen, 2001; Raychaudhuri, 2014). Diferansiyel denklemlerin öğrenimi ve öğretimi sürecinde karşılaşılan zorluklar, kaynağı ve sahadaki örneklerine yer verilmek suretiyle; kavramsal anlama yerine işlemsel anlama, muhakeme zorluğu, kavram yanılgısı ve son olarak da temsiller arası geçiş zorluğu başlıkları altında değerlendirilmiştir.

\subsection{Kavramsal Anlama Yerine İşlemsel Anla- ma}

Anlamanın doğasında yer alan kavramsal bilgi ve işlemsel bilgi terimleri; kullanıldıkları ortam, konu ve bağlama göre farklı anlamlara gelebilmektedirler. Matematik eğitimine yönelik çalışmalarda geçen bu terimlerin yerine, teolojik-şematik bilgi, ilişkisel-kurallı bilgi, yapısal-teknik bilgi gibi farklı terminolojiler de kullanılmaktadır (Haapasalo ve Kadijevich, 2000). Bu sinıflamalarda bilgi türü ve dolayısıyla anlama sürecinin iki kutuplu yapısına dikkat çekilmektedir. Kavramsal anlama; bir konudaki teorik ilişkileri tanımlayabilme, açıklayabilme, yorumlayabilme ve kanitlayabilme gibi ileri matematiksel düşünme süreçlerini gerektirirken, işlemsel anlama; kural, algoritma, formül, işlem veya prosedürleri bilme, uygulama ve hesaplama özelliklerini içerisinde bulundurmaktadır (Haapasalo ve Kadijevich, 2000; Hiebert ve Carpenter, 1992). Kavramsal ve işlemsel bilgiyi, birbirini tamamlayan iki değişken olarak niteleyen Hiebert ve Carpenter (1992), problem çözümlerindeki başarının, her iki bilgi türüne verilen ağırlığın dengelenmesi ile sağlanabileceğini vurgulamıştır.

Diferansiyel denklem konu alanındaki öğrenmelerin işlemsel mi yoksa kavramsal mı olduğunu inceleyen bir dizi araştırma yapılmıştır. İlgili alandaki çalışmalar, geleneksel diferansiyel denklemler derslerinde kurallı öğrenmelerin daha baskın olduğunu ve hesap temelli yaklaşımların benimsendiğini göstermiştir (Arslan, 2010; Habre, 2000; Rasmussen, 2001). 
Rasmussen (2001), analitik yaklaşımların baskın olarak kullanıldığı diferansiyel denklem sınıflarındaki öğrencilerin, problem çözüme sürecinde ilişkileri anlamlandırmaksızın, işlemsel öğrenmeler gerçekleştirdiğini belirlemiştir. Benzer odağa sahip bir diğer çalışmada Arslan (2010), geleneksel siniflarda diferansiyel denklemler dersini alan öğrencilerin daha çok kural tabanlı öğrenmeler gerçekleştirdiğini belirlemiştir. İşlemsel öğrenmeye dayanan bilgiler, sadece belirli kalıplardaki (formüllerin ezbere uygulandığı) diferansiyel denklem problemlerinde başarılı olmayı sağlamaktadır. Geleneksel sinıflardaki diferansiyel denklemler derslerinde öğrencilerin, işlemsel akıcllık ve kavramsal anlama düzeylerini değerlendiren Rasmussen, Kwon, Allen, Marrongelle ve Burtch (2006), öğrencilerin rutin hesaplardaki başarısının ilişkisel anlamadaki başarısından üç kat daha yüksek olduğu sonucuna ulaşmıştır. Oysa diferansiyel denklemler, türev ve integral alma kurallarının uygulandığ 1 teknik bilgiye dayalı bir dersten daha fazlasıdır. Bir diferansiyel denklemi hesaplamakla birlikte, sonucun ne anlama geldiğini yorumlamak, kesin çözüme ulaşılamadığı durumda alternatif yollar vasıtasıyla yaklaşık çözümler üretmek de gereklidir. Zaten işlemsel bilgilere dayalı bir öğretim, sadece genel çözümü olan ve cebirsel yöntemler ile çözülebilen sınırlı sayıdaki diferansiyel denklemler üzerinde uygulanabilir (Upton, 2004). Gerçek hayattaki problem durumları genellikle lineer olmayan ve analitik çözümü bulunmayan diferansiyel denklem türleri ile modellendiğinden, bazı bilindik kalıpların ustalıkla uygulanması kavramsal anlamayı garanti etmez (Arslan, 2008). Geleneksel siniflardagerçek hayat problemlerine çoğu kez yer verilmez ve analitik yaklaşımlar ile çözülebilen öğretim içerikleri sunulur. Bu sebeple geleneksel paradigmaya göre yapılandırılmış ders kitaplarının da kavramsal anlama yerine kurallı öğrenmeleri desteklediği vurgulanmaktadır
(Habre, 2000). Örneğin verilen birkaç denklem arasından homojen olanın bulunması bilgi basamağını gerektirirken, homojen olmayan bir diferansiyel denklemin yazılması kavrama basamağını gerektirir. Habre'ye (2000) göre diferansiyel denklemin tipini belirlemek, denklemin karakteristik özelliklerinin farkındalığ1 için önemlidir ve işlemsel bilgiden kavramsal bilgiye geçilememesinin önündeki en belirgin engel, öğrencilerin diferansiyel denklemleri çözüm türlerine göre sınıflayamamasıdır. Aşağıda her iki bilgi türü için de birer örnek paylaşılmıştır. İşlemsel bilgi kullanımını gerektiren ilk örnekte bir başlangıç-değer problemi için belli koşullara göre çözüm aranırken; kavramsal bilgiyi destekleyen ikinci örnek ise mertebe, keyfi sabit ve başlangıç-değer kavramları arasındaki ilişkilerin açıklanmasını gerektirmektedir.

Örnek 1: $\frac{d y}{d x}=\left(\frac{-1}{x}\right) y+(x-1)$ diferansiyel denkleminin $y(6)=11$ başlangıç koşulunu sağlayan bir çözümünü bulunuz?

Örnek 2: Üçüncü mertebeden lineer ve homojen bir diferansiyel denklemin çözümünde kaç adet keyfi sabit elde edilir ve bu sabitlerin belirlenebilmesi için kaç başlangıç değerine ihtiyaç vardır, açıklayınız?

Öğrencilerin kavramsal anlamayı gerektiren düşünme süreçlerinde zorluk yaşamaları, kavram imajlarındaki sınırlılık ile de açıklanabilir (Allen, 2006; Donovan, 2002; Rasmussen, 2001). Bu çıkarımı destekleyen çalışmalardan birinde Donovan (2002), yüksek başarılı öğrencilerin kavram şemalarında diferansiyel denklemlerin "çözülmesi beklenen bir fonksiyon" olarak karşılık bulduğunu belirtmiştir. Özellikle, birinci mertebeden diferansiyel denklem çözümlerinin daha kolay anlaşılması için öğrencilerin kavram şemalarının geliştirilmesi gereklidir (a.g.e). Diferansiyel denklemlerde (örn: $a_{n} y^{(n)}+a_{n-1} y^{(n-1)}+\ldots+a_{1} y^{\prime}+a_{0} y=Q(x) \quad$ şeklindeki yapıya sahip olan yüksek mertebeden lineer 
diferansiyel denklemler) " $y$ " notasyonuna ilişkin kavram imajlarını inceleyen Rasmussen (2001), çoklu imaja sahip olan öğrencilerin ilişkisel düşünebildiğini belirlemiştir. Çalışma sonucunda ortaya çıkan imajlar "değişken" ve "bilinmeyen" olup; "y" notasyonunu "değişken" olarak yorumlayan öğrenciler, dinamik sistemleri diferansiyel denklemler ile daha kolay açıklayabilmiş; " $y$ " notasyonunu "bilinmeyen" olarak yorumlayan öğrenciler ise eğim alanı grafiğinde çizilen eğrileri doğru yorumlayabilmişlerdir (a.g.e). Kavram imajları ile birlikte bilginin zihinde işleme sürecinin belirlenmesi de anlama türü hakkında bilgi verebilir. Whitehead ve Rasmussen (2003), diferansiyel denklem sistemlerinin kavramsal olarak geliştirilmesi sürecini, zihinsel işlemlerin kullanılması ile açıklamaya çalışmıştır (akt. Allen, 2006). İlgili araştırmada, zihinsel işlemler ile değişim oranı, nicelleştirme ve fonksiyon-değişken şemaları arasındaki etkileşime atıf yapılmış, diferansiyel denklem problemlerinin çözümlerinde öğrencilerin karşılaştıkları zorlukların genellikle "zayıf kavramsal ilişkiler" yüzünden kaynaklandığına dikkat çekilmiştir.

\subsection{Muhakeme Zorluğu}

Muhakeme; bir problem durumunun çözümünde akılcı bir sonuca ulaşmak için ortaya konan ilişkilendirme, argüman geliştirme, doğrulama ve ispatlama gibi çabaların sistematik bütünüdür (Brousseau ve Gibel, 2005). İleri matematik konularında muhakeme, daha çok ispat yapabilmek için gerekli bir ön beceri olarak görülmekle birlikte, aslında diğer tüm matematiksel becerilerin kullanıldığ ve kişiye göre farklılık gösteren bir tür matematiksel düşünme sistemidir. Bu bağlamda diferansiyel denklem problemlerinin çözümlerinde uygulanacak stratejilerin belirlenmesi için kural bilgisine sahip olmak önemlidir, ancak çözümün değerlendirilmesi ve doğrulanması için muhakeme becerisine de ihtiyaç vardır (Upton, 2004).
Diferansiyel denklem konu alanında öğrencilerin yaşadıkları muhakeme zorlukları genellikle modelleme süreci kaynaklıdır. Birçok çalışmada bir günlük hayat probleminin diferansiyel denklemler yardımıyla modellenmesi sürecinde veya diferansiyel denklem ile modellenmiş bir problem çözümünün yorumlanması sürecinde öğrencilerin yaşadıkları zorluklara dikkat çekilmektedir (Allen, 2006; Duvall, 2005; Kwon, 2009). Özellikle, dinamik sistemlerin modellenmesi sürecinde diferansiyel denklemlerden yararlanılır ve bu sistemlerde, bir değişkenin diğer bir değişken üzerindeki (zamandaki değişime göre) etkileri, parametrik bileşenler üzerinden açılanır (Keene, 2007). Örneğin, aynı yaşam alanını paylaşan iki hayvan popülasyonu dikkate alındığında, bir türün sayısındaki değişim diğer türü etkileyecektir ve popülasyonların değişim oranlarında barınma ve beslenme ihtiyacı gibi bazı değişkenler belirleyici role sahip olacaktır. Bu sebeple diferansiyel denklem problemlerinin çözümünde en çok ihtiyaç duyulan muhakeme türü parametrik muhakemedir (Allen, 2006). Parametrik muhakeme bir niceliğin zamana göre değişiminin diğer nicelikler üzerindeki etkilerini yorumlama ve nicelikler arasında ilişkili oranlar kurma yeteneğidir. İlgili araştırmalar, parametrik muhakeme yeterliğine sahip olmayan öğrencilerin, dinamik sistemlerin modellendiği diferansiyel denklem problemlerini çözmekte de zorluk yaşadıklarını ortaya koymuştur (Duvall, 2005; Keene, 2007). Çünkü zamana göre değişim oranının yorumlanması anlamına gelen parametrik muhakeme, gerçek hayat problemlerini diferansiyel denklemler ile çözebilmek için bir araç olarak kullanılmaktadır. Parametrik muhakeme yapabilen öğrenciler, yükseköğretim matematiğindeki ilişkili oranlar problemi üzerinde cebirsel ve geometrik olarak düşünebilirler (Allen, 2006).

Geleneksel sinıflardaki öğrenciler, muhakeme becerisi gerektiren diferansiyel denklem prob- 
lemlerinde zorluk yaşayabilmektedir. Yüksek mertebeden diferansiyel denklemleri kolayca hesaplayabilen birçok öğrencinin, diferansiyel denklemlerin yapı taşlarından olan değişken ve parametre gibi kavramları açılayamadıkları ve problem çözme sürecindeki rolünü yorumlayamadıkları belirlenmiştir (Allen, 2006). Diferansiyel denklemlerdeki muhakeme sürecini soyutlama basamakları (içselleştirmeyoğunlaştırma-yeniden düzenleme) üzerinden değerlendiren Duvall (2005), değişken ve parametre kavramları üzerine yoğunlaşmıştır. Çalışma sonuçları, parametre kavramına yönelik anlama düzeyi "yoğunlaştırma" seviyesinde olan öğrencilerin; türev-eğim ilişkisini anlama, parametre ve fiziksel değişimleri ilişkilendirme, değişkenleri bir nesne gibi kullanma ve farklı temsiller arası dönüşüm yapma becerilerine sahip olduğunu göstermiştir. Diğer yandan, parametre kavramına yönelik anlama düzeyi "içselleştirme" seviyesinde kalan öğrencilerin, parametre ve fiziksel değişim arasında ilişki kuramadığı belirlenmiş, değişken ve parametreleri ayırmakta zorlandıkları gözlenmiştir. Diferansiyel denklemlerde parametrik muhakemeden yalnızca bağlamsal yapılı problemleri çözmek için değil ayrıca formel yapılı problemleri anlamlandırmak için de yararlanılır. Öğrencilerin parametrik düşünme bağlamında yaşadıkları eksiklik, diferansiyel denklemlerin cebirsel formlarının anlamlandırılmasını da olumsuz etkileyebilir. Örneğin, $\frac{d y}{d t}=V(t)=m t+5,(m \in I R) \quad$ şeklinde verilen lineer diferansiyel denklemde $m$ parametresinin değişen değerlerine karşılık $V$ doğru ailesinin farklılaştı̆̆ına dikkat ediniz. Bu diferansiyel denklemin, serbest düşüme hareketini modellediği düşünülürse (hava direncinin ihmal edildiği durumda) cismin serbest düşüme hareketinin $y^{\prime \prime}=V^{\prime}(t)=m$ parametresinin kendisi olduğu açıkça görülmektedir. Bu örnekte, bağımsız değişken ve parametredeki değişime göre dife- ransiyel denklemin genel çözümü de farklılaşmaktadır.

Diferansiyel denklemler dersinde öğrencinin bilgi şemasının sarsılmasıyla yeni ilişkilerin kurulmasını sağlayacak problem durumlarını kullanmak yerine, tek çözüm yolu ile kesin cevaba ulaştıracak nitelikteki içeriklerden yararlanmak, gerçekçi bir muhakemenin ortaya çıkması önündeki engellerdendir (Habre, 2000; Kwon, 2009; Rasmussen, 1997). Bu bağlamda öğrencilerin muhakeme sürecinde yaşadıkları zorluk, öğretim sürecinde yararlanılan kaynaklar ve öğreticilerin tercih ettikleri örnekler ile ilişkili olabilir. Örneğin Lithner (2004), yüksek matematik derslerinde tercih edilen örnekleri, içeriğinde yer alan muhakeme türüne göre değerlendirmiş; çalışma sonuçları, örneklerin önemli bir bölümünün benzer rutin işlemler kullanılarak, algoritmik muhakeme yardımıyla çözülebildiğini göstermiştir.

\subsection{Kavram Yanılgısı}

Bireyin doğru olarak kabul ettiği ancak yanlış kavramsallaştırmalara dayanan sistematik hatalar, kavram yanılgısı olarak tanımlanmaktadır (Zembat, 2010). Diferansiyel denklemler konusunda gözlenen yanlış kavramsallaştırmaların bazı nedenleri; genelleme eğilimi, formal ve sezgisel bilgi çatışması ve tersinirlik karmaşasıdır (Rasmussen, 1997; Raychaudhuri, 2008). Bu kapsamda ele alınacak olan ilk yanılgı, özel diferansiyel denklemler için geçerli olan bazı kuralların genelleştirilmesidir. Diferansiyel denklem problemlerinde genel, özel ve tekil çözüm kavramlarının tanımları açık ve belirgin olmasına karşın, bu kavramlar öğrenciler tarafından birbiri ile karıştırılmaktadır (Rasmussen, 1997). Genelleme eğilimi, denge çözümleri bulunarak elde edilen özel denklemlerin, diğer türdeki diferansiyel denklemler için de bir çözüm oluşturacağının düşünülmesidir (Zandieh ve McDonald, 1999). Rasmussen'in (1997) 
çalışmasında ortaya çıan bulgular $\frac{d y}{d t}=t+1$ ve $\frac{d y}{d t}=y-t$ diferansiyel denkleminin çözümünde, öğrencilerin özel çözümlere bakmaksızın, ifadeleri sıfıra eşitleyerek $y=t$ ve $t=-1$ için bir denge çözümü bulma eğilimde olduklarını göstermiştir. Buradaki yanılgı, denge çözümlerine, diferansiyel denklemin sıfıra eşitlenmesi işlemiyle ulaşılmasıdır. Oysa $\frac{d y}{d t}=y-t$ için denge çözümünün $y=t$ şartıyla sağlanabileceğine karar veren öğrenci, bunun özel bir çözüm olduğunu aklından çıkarmamalıdır. Bu çalışmaya katılan öğrencilerin yaklaşık yarısı otonom fonksiyonlar için geçerli olan bir çözümü genelleştirmişlerdir (a.g.e). Denge çözüm şartlarının otonom diferansiyel denklemler üzerine genelleştirilmesi yanılgısının ele alındığı bir diğer araştırmada Zandieh ve McDonald (1999), katılımcıların yaklaşık üçte birinin, $\frac{d y}{d t}=0$ özel çözümünü kullanarak bir denge çözümü belirlemeye çalıştı̆̆ını gözlemiştir. Allen (2006) ise öğrencilerin diferansiyel denklem çözümlerini fonksiyonun tamamı üzerinde düşünmek yerine nokta, aralık ya da nümerik değerler ile sınırladığına dikkate çekmiştir. Bir kuralın, geçerli olmayan başka bir durum üzerinde uygulanması veya denge çözümlerinin diferansiyel denklem için bir özel çözüm olarak görülmemesi, öğrencilerin yanılgıya düşmelerine neden olmuştur.

Sezgiye dayalı bilgilerin formal bilgiler ile çatışması durumuna verilebilecek en dikkat çekici örnek, fonksiyonların durağanlığı düşüncesidir. Öğrencilerde fonksiyonun değişmezliği, hareket etmezliği düşüncesi yer almaktadır (Duvall, 2005). Bu durum, diferansiyel denklemin tüm aralıktaki çözümlerinin aynı eğime doğru yöneleceği şeklinde bir yanılgı ortaya çıkarmaktadır. Oysa diferansiyel denklem kavramı, temellerini anlık değişimler toplamının, olaylar üzerindeki yansımaları üzerine kurmaktadır. Öte yandan grafik temsilleri, kavramsal anlamayı geliştirebileceği gibi yanlış yorumlama durumunda bilişsel zorluklara da neden olabilir. Bu zorluğun oluşmasını tetikleyecek düşüncelerden biri grafiklerin, gerçek durumların birebir yansıması olarak görülmesidir. Örneğin, bir sarkacın konumunu resmeden açı-zaman grafiğinde, belirli bir zamandaki konumu araştıran öğrenci, çözüme grafikten birebir yararlanarak ulaşma çabası ve yanılgısı sergileyebilir. Bu gibi öğrenen temelli bazı zorluklar, grafik verilerinin eksik veya yanlış yorumlanmasından kaynaklanmaktadır. Nitel (grafiksel) yaklaşımlarda hedef, diferansiyel denklemlerin çözüm davranışlarını görsel olarak resmetmektir. Bu çözüm grafikleri ise ancak eğim alanlarının çizilmesi ile belirlenebilir. Bu konuda ortaya çıkan iki tür yanılgı Habre'nin (2000; 2003) iki farklı çalışmasında sırasıyla şu şekilde ifade edilmektedir:

(1) Öğrencilerin büyük çoğunluğuna göre genel çözüm karakteristiği bulunurken kullanılabilecek tek yaklaşım analitiktir ve nitel yaklaşımlar sadece yerel değerler için bir fikir verir (Habre, 2000).

Oysa birçok diferansiyel denklem probleminin çözümünde analitik yaklaşımlar kullanılmazken; nitel yaklaşım, genel çözüm karakteristiklerinin tamamını içerir.

(2) Bazı öğrenciler, çözüm grafiklerine ulaşırken eğim alanından yararlanmak yerine ilkel fonksiyonun (diferansiyeli alınmış) grafiğini kullanır. Çünkü öğrencilere göre eğim alanlarını çizmek zaman alıcı ve zordur (Habre, 2003).

Ancak bu çizim (her ne kadar türev-ilkel fonksiyon grafikleri arasındaki geçiş gibi görünse de) sadece tek çözümü olan kapalı fonksiyonlar için doğru sonuçlar verir, oysa çözüm fonksiyonunun birden fazla olması muhtemeldir. Türev ve integral işleminin sadece birbirinin tersi olarak yorumlanması da diferansiyel 
denklem çözümlerinde yanlış çıkarsamalara yol açmaktadır (Raychaudhuri, 2008). Örneğin bir diferansiyel denklemin integralini alarak bir çözüm elde eden öğrencinin, ilkel fonksiyonun tekrar türevini alarak aynı diferansiyel denkleme ulaşma çabası sadece $y^{\prime}-f(t)=0$ formundaki birinci mertebeden diferansiyel denklemler için geçerlidir. $\mathrm{Bu}$ tersinir işlem, $y^{\prime}-f(t, y)$ formu için doğru diferansiyel denklemi üretmeyecektir. Çünkü $y^{\prime}-f(t, y)$ diferan- siyel denklemini sağlayan $y-\phi(t)$ şeklindeki türevlenebilir herhangi bir fonksiyon, ilgili tüm $t$ değerleri için bir çözüm oluşturabilir, ancak diferansiyel denklemin integrallenmesi ile olası tüm çözümlere ulaşılamaz. Raychaudhuri'ye (2008) göre diferansiyel denklemden çözüm fonksiyonuna geçiş sürecindeki bu tür işlem adımları, süreçlerin nesne olarak algılanmasına yol açmaktadır ve tersi yöndeki geçişlerde geçerli sonuçlara ulaşılmasını engellemektedir (Şekil 1).

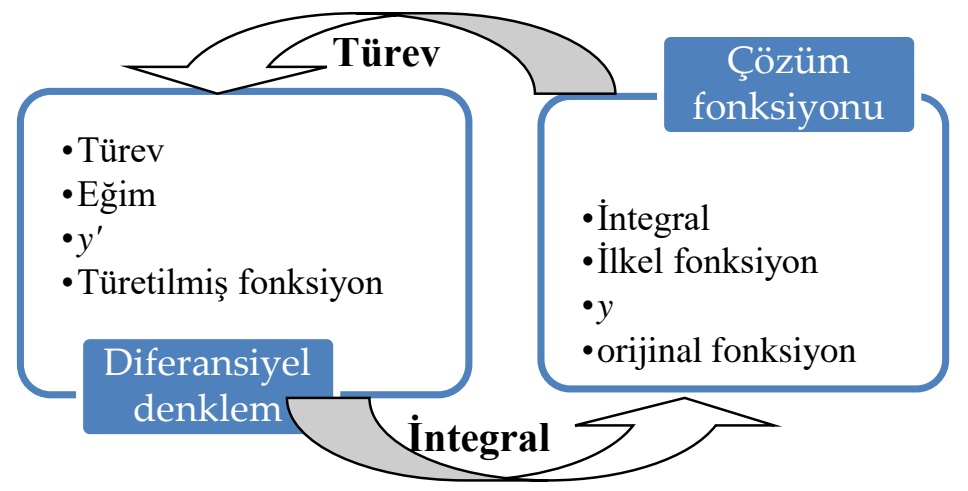

Şekil 1. Öğrencilerin Algıladığı Süreç-Nesne İkiliği (Raychaudhuri, 2008)

\subsection{Temsiller Arası Geçiş Zorluğu}

En genel anlamiyla temsiller, soyut kavram veya sembolleri, gerçek dünya içinde somutlaştırma yoluyla modelleme işlemi olarak tanımlanabilir (Delice ve Sevimli, 2016). Çoklu temsiller, öğrencilerin matematik konularını anlamalarını kolaylaştırması, problem çözümlerine farklı yollardan yaklaşmalarını sağlaması ve bilişsel ilişki kurmalarına yardımcı olması yönüyle birer avantaj olarak görülebilir. Diferansiyel denklemlerin sunumunda en sik kullanılan üç temsil türü denklem, grafik ve veri tablosu olup bu temsillerin kullanılmasıyla ortaya çıkan çözüm yaklaşımları sırasıyla analitik, nitel ve nümeriktir (Habre, 2000; Hunt ve diğer., 2009; Rasmussen, 1997).

Geleneksel sinıflardaki en büyük zorluklar, öğrencilerin diferansiyel denklemin cebirsel ve grafik temsilleri arasında ilişki kuramamaları, diferansiyel denklem ve eğim alanları arasında eşleştirme yapamamaları ve hangi problem türlerinde hangi yaklaşımların kullanılıp kullanmayacaklarının farkında olmamalarıdır (Buendia ve Cordero, 2013; Habre, 2000). Donovan'ın (2002), anlama-çoklu temsil ilişkisi üzerine yaptığı çalışmada, matematik bölümü öğrencilerinin farklı temsiller arasında ilişki kurma becerisi yönüyle zayıf oldukları, diferansiyel denklemin genel özellikleri ve biçimsel yönü ile ilgili daha çok bilgiye sahip oldukları belirlenmiştir. Diferansiyel denklem konusunda grafik kullanımının kendisine çok anlamlı gelmediğini belirten matematik bölümü öğrencilerinin işlemsel süreçlerde başarılı oldukları ancak kavram bilgisi yönüyle yeterli olmadıkları gözlenmiştir (a.g.e). Şekil 2'de verilen eğim 
alanı ve diferansiyel denklem eşleştirmesi etkinliği ile öğrencilerin temsil farkındalıklarını değerlendiren Rasmussen (2001), öğrencilerin temsiller arası geçiş sürecinde genellikle başarıl1 olduğunu kaydetmiştir. Bununla birlikte, çalışmaya katılan altı öğrenciden üçünün cebir temsilinden grafik temsiline geçiş sürecinde, yanlış kavramsallaştırmalara dayandığı (örneğin, türevin sıfır olduğu yerde denge çözümü vardır) belirlenmiştir (a.g.e).

$$
\begin{aligned}
& \text { a) } \frac{d y}{d t}=t-1 \\
& \text { b) } \frac{d y}{d t}=t+1 \\
& \text { c) } \frac{d y}{d t}=y+1 \\
& \text { d) } \frac{d y}{d t}=y^{2}+y \\
& \text { e) } \frac{d y}{d t}=y\left(y^{2}-1\right)
\end{aligned}
$$
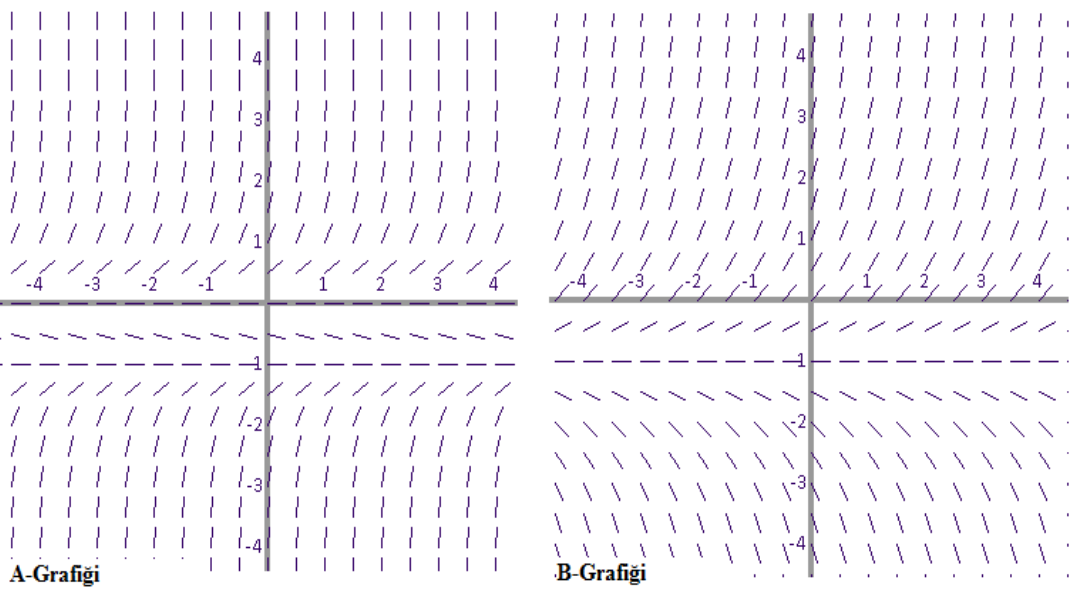

B-Grafiği

Yukarıdaki eğim alanları hangi diferansiyel denklemlere aittir, açıklayınız?

Şekil 2. Diferansiyel Denklemlerde Temsiller Arası Geçiş

Temsiller arasındaki geçiş sürecinde karşılaşılan bir diğer durum öğrencilerin farklı temsil kullanımına ilişkin epistemolojik inançları ile ilgilidir. Rasmussen (1997) ve Upton'un (2004) yürüttüğü iki farklı çalışmanın ortak bulgularında, öğrencilerin grafik ve nümerik temsilleri kullanmaktan yana gönülsüz oldukları ve bu temsillerin kullanıldığı problemleri anlamakta da zorluk yaşadıkları ifade edilmiştir. Diferansiyel denklemin çözümünde eğim yaklaşımının gerekli olduğu problem türlerinde (örneğin $y^{\prime}=$ $2 y-y^{2}$ diferansiyel denkleminin çözümü problemi gibi) analitik teknikleri kullanarak çözüme ulaşmaya çalışan adayların başarısız olduğu gözlenmiştir (Habre, 2000). Özellikle analitik yaklaşımlar ile çözülemeyen diferansiyel denklem problemlerinde bile öğrencilerin cebirsel temsilleri kullanmaya istekli olmaları, epistemolojik inanç faktörü ve alternatif yaklaşımlara ilişkin farkındalık eksikliği ile açıklanabilir. Sayısal hesaplama yöntemlerinin kullanılabile- ceği bir diferansiyel denklemde, yaklaşık değer bulmak için tablo verilerini yorumlayamayan bir öğrenci, temsil bilgisi yönüyle eksiktir. Öğrencilerin epistemolojik inançları da tek temsil kullanımını etkilemektedir. Örneğin Rasmussen'in (1997) çalışmasındaki bazı öğrenciler, diferansiyel denklem problemlerindeki grafik çizimlerini bir çözüm sonucu olarak kabul etmemiştir. Çünkü bu öğrenciler geçmiş deneyimlerine dayanarak çözüm kelimesini bir fonksiyon olarak tanımlamaktadır. Ne zaman bir diferansiyel denklem çözümü yapılmak istense bu öğrencilerin (cebirsel) bir ilkel fonksiyona ulaşma çabası içerisinde olduğu belirlenmiştir (a.g.e). Habre (2003) ise diferansiyel denklem çözümlerinde cebirsel temsillerin gücüne olan inancı açıklarken, bir öğrencinin geometrik çözümlere ilişkin şu görüşünü paylaşmıştır:

“Diferansiyel denklem problemlerinin çözümünde grafikler bize kesin bir çözüm vermez, çözümün 
genel fikrini verir, çözüm ile ilgili eğer bir cebirsel formüle sahipseniz bu bilmemiz gereken her şeyi içerir"

Ancak bir öğrenci alternatif çözüm yaklaşımlarını kullanma bilgisine sahip olmasına rağmen analitik yaklaşımı kullanmakta 1srarcı oluyorsa, bu o öğrencinin cebirsel temsil ile olan çözüme daha fazla güvendiğini ve dolayısıyla epistemolojik inancına göre bir tercihte bulunduğu gösterir. Bu bulgular, kesin ve doğru bir çözüm için grafik temsiline kıyasla cebirsel temsile daha fazla güven duyulduğunu göstermektedir. Şüphesiz bu güvenin oluşmasında geleneksel öğretim ortamı, cebirsel içeriklerin baskın olduğu ders kaynakları ve öğreticilerin bakış açıları gibi bir dizi değişkenin etkisi vardır. Habre'ye (2000) göre birçok öğretici, nitel yaklaşımların vazgeçilmez enstrümanı olan eğim alanları çizme sürecini, zaman kaybı olarak görmekte ve ders işlenişi sırasında geometrik çözüm süreçleri üzerinde durmamaktadır. Gerçekten de bir diferansiyel denklemin eğim alanlarına ilişkin grafiği el ile çizmek zaman almaktadır. Teknolojideki gelişimlere paralel olarak diferansiyel denklem grafiklerini çizebilen yazılımların da üretilmesi, grafik temsillerinin öğretim ortamlarındaki kullanışlılığını arttırmıştır.

\section{ALTERNATIIF YAKLAŞIMLAR}

Diferansiyel denklemler konusunun öğrenim ve öğretiminde yaşanan ve bir önceki bölümde ifade edilen zorlukların giderilmesi için öğretim sürecinde farklı hesap yöntemleri ve öğretim yaklaşımlarının kullanılması gerektiğine dikkat çeken literatürde çok sayıda çalışma mevcuttur (Arslan, 2010; Habre, 2000; Kwon, 2009; Rasmussen, 1997; Rasmussen ve diğer., 2006; Wagner, Speer ve Rossa, 2007). Aşağıda paylaşılan alternatif yaklaşımlar, bir lisans dersi içerisine sıkıştırılması beklenen öneriler olarak düşünülmemelidir, ancak bir alan olarak diferansiyel denklemlerin öğretim felsefesi içerisinde yer alması hususunda kabul görmüş yaklaşımlar olarak değerlendirilmelidir.

\subsection{Diferansiyel Denklem Hesabında Yöntem Çeşitliliği}

Geleneksel sinıflarda diferansiyel denklemlerin çözümlerinde cebirsel hesap yöntemleri baskın olarak kullanılırken, bu yöntemler sinırlı sayıdaki diferansiyel denklem problemleri için bir çözüm üretebilir. Analitik yaklaşım, belli başı bazı formül ve tekniklerin uygulanması ile verilen bir diferansiyel denklemin cebirsel çözümlerini bulma sürecini kapsamaktadır (Arslan, 2008). Örneğin, $\frac{d y}{d x}+P(x) y=Q(x)$ şeklindeki birinci mertebeden lineer bir diferansiyel denklemin genel çözümünü $y=c e^{-\int P(x) d x}$ formülünü kullanarak belirlemek analitik yaklaşımları ihtiva eder. 
Değer tablosu

\begin{tabular}{lll}
$x$ & $y$ & $\frac{d y}{d x}$ \\
\hline-1 & 1 & -0.99 \\
\hline 0 & 1 & -1 \\
\hline 0 & 0 & 0 \\
\hline 1 & -1 & 0.99 \\
\hline 1 & -2 & 1.98 \\
\hline 2 & 2 & -1.98
\end{tabular}

Eğim alanı grafiği

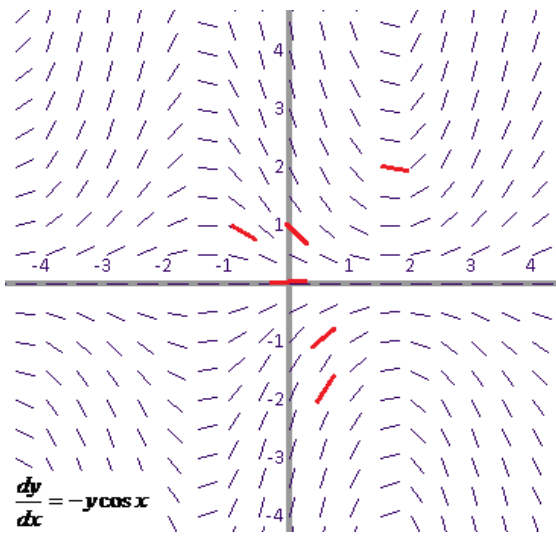

Çözüm eğrisi (integral) grafiği

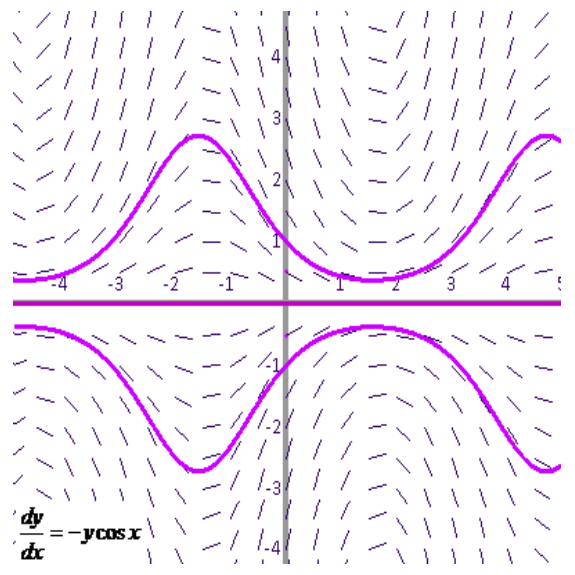

Şekil 3. Bir Diferansiyel Denklemin Çözümünde Nitel Yaklaşım Kullanımı

Analitik yaklaşımların tatbik edilemediği durumlarda alternatif olarak nitel ve nümerik yaklaşımlardan yararlanılabilir. Hem bu sayede analitik yollardan çözülemeyen birçok diferansiyel denklem problemi için geometrik veya nümerik çözüm sistemleri oluşturulur. Nitel yaklaşımlar yoluyla, eğim alanı veya yön alanlarını kullanmak suretiyle diferansiyel denklemlerin geometrik çözümlerine ulaşılabilir (Buendia ve Cordero, 2013). Eğim alanlarını sağlayan integral eğrileri çizilerek diferansiyel denklemler için çözüm fonksiyonu veya fonksiyon ailesi belirlenebilir. Diferansiyel denklem hesabında geometrik yöntemlerin kullanımına ilişkin bir örnek Şekil 3'te paylaşılmıştır. Buna göre $\frac{d y}{d x}=-y \cos x$ diferansiyel denkleminin nitel yaklaşımlar ile çözümü için aşağıdaki işlem adımları takip edilebilir: (1) cebirsel olarak verilen bir diferansiyel denklemin önce değer tablosu yardımıyla bazı özel noktalardaki eğimleri belirlenir, (2) bu özel noktalar için belirlenen eğimler, grafik üzerinde işaretlenerek eğim alanları oluşturulur, (3) grafik verilerini sağlayan integral eğrileri çizilerek diferansiyel denklem için bir çözüm sistemi elde edilir. Çözüm grafiğinde verilen integral eğrisinin $y=c e^{-\sin x}, \quad(c \in I R)$ genel çözüm denklemini sağladığı görülmektedir.
Diferansiyel denklemin verilen bir noktadan geçen bir özel çözümünün yaklaşık değerini bulmak için nümerik yaklaşımlardan yararlanılabilir (Arslan, 2008). Bu yaklaşım ile formülün doğrudan verilmediği durumlarda, denklem hakkındaki nicel bilgilerden yola çıkılarak ve bir hesaplama aracından yararlanılarak, diferansiyel denklemin belirli bir noktasındaki yaklaşık değeri hesaplanabilir. Diferansiyel denklemin nümerik olarak hesaplanabilmesi için çözümün diferansiyel denkleme ve başlangıç değerlerine sürekli bağımlı olması gerekir. Aksi takdirde, elde edilen sayısal çözümlerdeki hata payları yükselir ve gerçek çözümden çok uzak sonuçlar üretilir. Diferansiyel denklemlerin nümerik olarak hesaplanması sürecinde kullanılan başlıca yöntemler; Euler yöntemi, Taylor serisi yöntemi, Newton-Rapson yöntemi ve Runge-Kutt yöntemidir (Hunt ve diğer., 2009). Nitel ve nümerik çözüm yaklaşımları genellikle birbirlerini destekler. Örneğin, bir diferansiyel denklem için çözüm eğrisi oluşturulurken $(x, y)$ noktalarındaki eğim değerlerinin belirlenmesi gerekir. Analitik, nitel ve nümerik yaklaşımların her birinin güçlü ve zayıf yönleri vardır ve bu sebeple öğretimin bu üç yaklaşımdan herhangi birinin hâkimiyetinde yürütülmesi sakıncalıdır (Arslan, 2008). Öğretim içeriğinde farklı problem durumlarından yarar- 
lanmak ve farklı matematiksel düşünme yapısına sahip öğrencilerin derse katılımlarını sağlamak için birden çok çözüm yaklaşımının ilişkilendirilerek kullanılması önerilmektedir (Burtch, 2005; Duvall, 2005; Habre, 2012). Böylece, bir hesap yönteminin eksik kaldığı hususlarda bir diğer yöntem ilave bilgiler katarak bu eksikliği tamamlayacaktır.

\section{2 Öğretim Yaklaşımlarında Çeşitlilik}

Diferansiyel denklemlerin öğretiminde iki tür yaklaşımın daha sık kullanıldığı ilgili literatürde ifade edilmiştir. Bunlar; teknoloji destekli yaklaşım ve gerçekçi matematik eğitimi yaklaşımıdır (Camacho-Machín ve Guerrero, 2015; Habre, 2012; Kwon, 2009; Miller ve Upton, 2008; Rasmussen ve diğer., 2006; Wagner ve diğer., 2007). İleri hesaplama teknolojisine sahip matematik yazılımlarının geliştirilmesiyle birlikte matematik öğretiminde farklı temsillerin kullanılabileceği, soyut kavramların görselleştirilerek somutlaştırılabileceği fırsatlar oluşmuştur. Dinamik sistemlerin modellenmesinde kullanılan ve analitik yaklaşımlar ile hesaplanamayan diferansiyel denklem türlerine çözüm bulma ihtiyacı, mesleki yaşamlarında matematiğin uygulamalarını kullanan bazı bölümlerde (örneğin, istatistik ve mühendislik) teknoloji destekli öğretime olan ilgiyi arttırmıştır. Özellikle 1990'lı yılların başından itibaren, geleneksel diferansiyel denklem sinıflarındaki ders içeriği ve öğretim çıtıları sorgulanmaya başlanmış; derslerde baskın olarak kullanılan analitik yaklaşımlara kıyasla teknoloji destekli öğretim süreçlerinin etkililiği araştırılmıştır (Camacho-Machín ve Guerrero, 2015; Rasmussen, 2001). Diferansiyel denklemlerin analitik, nitel ve nümerik çözümleri arasında bağlantı kurmak için teknoloji desteğinin vazgeçilmez bir unsur olduğu yine birçok çalışmada ifade edilmiştir (Arslan, 2010; Camacho-Machín ve Guerrero, 2015). Habre (2012), analitik yaklaşımların nitel yaklaşımlar ile desteklendiği teknoloji destekli diferansiyel denklem siniflarında, öğrencilerin matematiksel yazma ve ilişkisel düşünme becerilerinin geliştiğini kaydetmiştir. Diferansiyel denklem derslerinde, bilgisayar cebiri sistemi kullanımının öğretim sürecindeki katkıları; çözüm fonksiyonuna ilişkin tahminde bulunma, sezgisel düşünme, yüksek mertebeden hesapları kisa zamanda ve doğru olarak gerçekleştirme, bağlamsal problemleri yorumlayabilme şeklinde sıralanabilir (Habre, 2003; Hunt ve diğer., 2009; Miller ve Upton, 2008; Rasmussen, 2001).

Diferansiyel denklem sinıflarında gerçekçi matematik eğitimi yaklaşımını odağına alan araştırmalarda genellikle sorgulamaya dayalı öğretim tekniğinden yararlanılmıştır (Kwon, 2009; Rasmussen ve diğer., 2006; Wagner ve diğer., 2007). Bu konudaki çalışmalardan birinde Kwon, Rasmussen ve Allen (2005), geleneksel ve sorgulamaya dayalı diferansiyel denklem sınıflarındaki öğretim çıktıları arasında işlemsel bilgiye göre anlamlı bir farklılığın gözlenmediğini ancak kavramsal bilgiler bağlamında sorgulamaya dayalı grup lehine pozitif yönde anlamlı sonuçların elde edildiğini belirlemiştir. Sorgulamaya dayalı öğretimin sosyal bağlamdaki etkilerini inceleyen Allen (2006), öğrencilerin kendi bilgilerini ve zorluklarını daha kolay ifade edebildiklerini gözlemiştir. Rasmusssen ve Kwon (2007) ise diferansiyel denklemler dersinde sorgulamaya dayalı öğretim aktiviteleri ile zenginleştirilmiş öğrenme ortamlarının geleneksel ortamlara kıyasla sağladığı avantajları sıralarken; matematiksel gerçekleri anlamlı hale getirerek kavramsal anlamayı desteklemesi, matematiksel muhakeme becerilerinin geliştirilmesine olanak tanıması, matematiği bilme ve yapmaya ilişkin pozitif inançlar oluşturması gibi çıtılardan söz etmişlerdir. 


\section{SONUÇ VE ÖNERİLER}

Bu derleme çalışmasının sonucunda, hem öğreticilerin hem araştırmacıların yararlanabileceği bazı çıktılara ulaşılmıştır. Diferansiyel denklemler dersini veren öğretim elemanları için öğrencilerin yaşadıkları birtakım yanılgı ve zorluklara ilişkin farkındalık oluşturabilecek içerikler paylaşılmıştır. Buna göre, geleneksel sınıftaki öğrencilerin belirli kalıptaki diferansiyel denklemler için analitik çözüm bulmaları, bu dersin temel kazanımı için yeterli değildir. Analitik yaklaşımlar ile çözülemeyen diferansiyel denklemlerin davranışlarını belirleyebilmek, değişken ve parametre kavramları ile diferansiyel denklem kavramı arasındaki ilişkileri açıklayabilmek, niceliklerin zamana göre değişimini parametrik muhakeme ile yorumlamak ve ayrıca diferansiyel denklem çözümlerinde nitel ve nümerik yaklaşımların farkında olmak, dersin diğer önemli çıktılarındandır. Diferansiyel denklemler konusunun öğrenim ve öğretiminde karşılaşılan yanılgı ve zorlukların giderilebilmesi için literatürde şu önerilere yer verilmiştir: (1) öğretim içeriğinin teknoloji destekli yaklaşımlar ile sunulması, (2) problem çözme sürecinde analitik, nitel ve nümerik yaklaşımların ilişkilendirilerek kullanılması, (3) dinamik sistemlerin modellenmesi sürecinde, öğrencilerin diferansiyel denklemleri kullanabilmeleri için gerçek hayat ile ilişkili problem durumlarının sinıf ortamına getirilmesi. Bu çalışma kapsamında ifade edilen yanılgı ve zorluklar yurtdışı ölçekli araştırmaların bir sentezini oluşturmaktadır. Ancak, yanılgı ve zorlukların oluşması sürecinde kültür ve bağlam önemli iki değişkendir. Örneğin ülkemizde lisans düzeyinde verilen diferansiyel denklemler dersi bir veya iki dönem içerisinde işlenmekte olup bu süreçte, birinci mertebeden denklemlerin uygulamaları ve yüksek dereceden bazı denklemlerin aykırı çözümlerine yer verilebilmektedir. Diferansiyel denklemler dersinde ders içeriğinin ve süresinin ülkelere göre farkll1ık göstermesi ile birlikte program türüne göre hedeflerin farklılaşması (örneğin, matematik ve mühendislik programlarmdaki farkllıklar) ve bazı diferansiyel denklem konularının farklı dersler içerisinde de sunuluyor olması (örneğin, adi diferansiyel denklemlerin nümerik çözümlerinin "nümerik analiz" dersi içerisinde sunulması) bu çalışma kapsamında ifade edilen zorlukların ve çözüm önerilerinin ülkemizdeki yansımalarını sınırlyor olabilir. Bu sebeple, ülkemizdeki diferansiyel denklemler dersinin müfredatında ve pedagojisinde ortaya çıkabilecek farklı yanılgı ve zorlukların belirlenmesi hususunda araştırmacılara önemli görevler düşmektedir. Diferansiyel denklem alanında yaşanan zorlukların belirlenmesi ve alternatif yaklaşımların etkililiğinin değerlendirilmesine ilişkin ülkemiz özelinde yapılacak araştırmaların, literatüre katkı sağlayacağı düşünülmektedir.

\section{Kaynakça}

Allen, K. (2006). Students' participation in a differerential equations class: parametric reasoning to understand systems. Unpublished doctoral dissertation. The Purdue University.

Arslan, S. (2008). Diferansiyel denklemlerin öğretiminde farklı yaklaşımlar ve nitel yaklaşımın gerekliliği. Milli Ĕ̆itim Dergisi, 179, 153-163.

Arslan, S. (2010). Traditional instruction of differential equations and conceptual learning. Teaching Mathematics and Its Applications, 29(2), 94-107. 
Artigue, M. (1992). Cognitive difficulties and teaching practices. in g. harel \& e. dubinsky (Ed.), The concept of function: Aspects of epistemology and pedagogy (pp. 109-132), Washington, DC: The Mathematical Association of America.

Brousseau, G. \& Gibel, P. (2005). Didactical handling of students' reasoning processes in problem solving situations. Educational Studies in Mathematics, 59(2), 13-58.

Buendia, G. \& Cordero, F. (2013). The use of graphs in specific situations of the initial conditions of linear differential equations. International Journal of Mathematical Education in Science and Techno$\log y, 44(6)$, 927-937.

Burtch, C. M. (2005). Conjecturing as a classroom activity in differerential equations. Unpublished doctoral dissertation. The Arizona State University.

Camacho-Machín, M., \& Guerrero-Ortiz, C. (2015). Identifying and exploring relationships between contextual situations and ordinary differential equations. International Journal of Mathematical Education in Science and Technology, 46(8), 1077-1095.

Dana-Picard, T., \& Kidron, I. (2007). Exploring the phase space of a system of differential equations: different mathematical registers. International Journal of Science and Mathematics Education, 6(4), 695-717.

Delice, A. ve Sevimli, E. (2016). Matematik eğitiminde çoklu temsiller. Bingölbali, E., Arslan, S. ve Zembat, İ. Ö (Ed.), Matematik eğitiminde teoriler (ss. 519, 535), Ankara: Pegem Akademi Yayıncılık.

Donovan, E. J. (2002). Students' understanding of First-Order Differential Equations. Unpublished doctoral dissertation. University of New York.

Duvall, A. S. (2005). A case study of two students' concept images of parameter in a multi-representational differerential equations course. Unpublished doctoral dissertation. University of Northern Colorado.

Habre, S. (2000). Exploring students' strategies to solve ordinary differential equations in a reformed setting. Journal of Mathematical Behavior, 18 (4), 455-472.

Habre, S. (2003). Investigating students' approval of a geometric approach to differential equations and their solutions. The International Journal of Mathematical Education in Science and Technology, 34(5), 651-662.

Habre, S. (2012). Improving understanding in ordinary differential equations through writing in a dynamical environment. Teaching Mathematics and Its Applications, 31(3), 153-166.

Haapasalo, L., \& Kadijevich, D. (2000). Two types of mathematical knowledge and their relation. Journal für Mathematik-Didaktik, 21(2), 139-157.

Hiebert, J., \& Carpenter, T. P. (1992). Learning and teaching with understanding. In D. A. Grouws (Ed.), Handbook of research on mathematics teaching and learning (pp. 65-97), New York: Macmillan.

Hunt, B. R., Lardy, L. J., Lipsman, R.L., Osborn, J. E., \& Rosenberg , J. M. (2009). Differential equations with maple (3rd edition), USA: John Wiley \& Sons Inc.

Keene, K. (2007). A characterization of dynamic reasoning: Reasoning with time as parameter. Journal of Mathematical Behavior, 26(3), 230-246. 
Kwon, O. N., Rasmussen, C., \& Allen, K. (2005). Students' retention of mathematical knowledge and skills in differential equations. School Science and Mathematics, 105(5), 1-13.

Kwon, O. N. (2009). Conceptualizing the realistic mathematics education aproach in the teaching and learning of ordinary differential equations. http://www.cimm.ucr.ac.cr/ojs/index.php/eudoxus/article/view/430. adresinden erişilmiştir.

Lithner, J. (2004). Mathematical reasoning in calculus textbooks exercises. Journal of Mathematical Behavior, 23, 405-427.

Miller, R. H., \& Upton, S. B. (2008). Computer manipulative in an ordinary differential equation course: development, implementation and assessment. Journal of Science Education and Technology, 11(2), 124-137.

Rasmussen, C. (1997). Qualitative and numerical methods for analyzing differential equations: A case study of students' understandings and difficulties. Unpublished doctoral dissertation. University of Maryland.

Rasmussen, C. (2001). New directions in differential equations: A framework for interpreting students' understandings and difficulties. Journal of Mathematical Behavior, 20, 55-87.

Rasmussen, C., Kwon, O. N., Allen, K., Marrongelle, K., \& Burtch, M. (2006). Capitalizing on advances in mathematics and K-12 mathematics education in undergraduate mathematics: An inquiryoriented approach differential equations. Asia Pacific Education Review, 7(1), 85-93.

Rasmussen, C., \& Kwon, O. N. (2007). An inquiry-oriented approach to undergraduate mathematics. The Journal of Mathematical Behavior, 26(3), 189-194.

Raychaudhuri, D. (2008). Dynamics of a definition: a framework to analyse student construction of the concept of solution to a differential equation. International Journal of Mathematical Education in Science and Technology, 39(2), 161-177.

Raychaudhuri, D. (2014). Adaptation and extension of the framework of reducing abstraction in the case of differential equations. International Journal of Mathematical Education in Science and Technology, $45(1), 35-57$.

Sezer, M. ve Daşcıoğlu, A. (2010). Diferansiyel Denklemler I. Bursa: Dora Yayınları.

Upton, S. D. (2004). Students' solution strategies to differerential equations problems in mathematical and nonmathematical contexts. Unpublished doctoral dissertation. The Arizona State University.

Wagner, J. F., Speer, N. M., \& Rossa, B. (2007). Beyond mathematical content knowledge: A mathematician's knowledge needed for teaching an inquiry-oriented differential equations course. The Journal of Mathematical Behavior, 26(3), 247-266.

Zandieh, M., \& McDonald, M. (1999). Student understanding of equilibrium solutions in differential equations. In F. Hitt \& M. Santos (Eds.), Proceedings of the 21st PME(NA) (pp. 253-258). Columbus, OH: ERIC.

Zembat İ. Ö. (2010). Kavram Yanılgısı Nedir?. Özmantar, M. F., Bingölbali, E. ve Akkoç, H. (Ed.), Matematiksel Kavram Yanılgıları ve Çözüm Önerileri (ss. 1-8). Ankara: Pegem Akademi Yayıncılık. 


\section{Extended Summary}

Differential equations are usually used while real-world problems are modeled in different disciplines. The models containing the relative change of two or more variables, such as dynamic systems, require partial differentiation. Although it is stated that differential equations are important and useful for realworld problems, there is limited content supporting this argument in the traditional learning environments (Kwon, 2009; Rasmussen, 2001). Especially in the last twenty years, challenges and misconceptions caused by traditional content and approaches which were used to teach differential equations were determined; alternative approaches which can be used to solve these difficulties were started to discuss (Artigue, 1992; Buendia \& Cordero, 2013; Burtch, 2005; Camacho-Machín \& Guerrero, 2015; Rasmussen, 1997). The studies done in order to reach current instructional objectives in the course of differential equations in the international arena were not reflected enough to the mathematics education literature in Turkey. The lack of a review study about differential equations in Turkish education systems can restrict the reflections of this subject in the context of Turkey. In the scope of the study, challenges and misconceptions which are lived by the students on differential equations are determined. Also, it has been discussed in the literature, to cope with these difficulties and determine what the supposed teaching approaches are.

The challenges encountered in the process of learning and teaching of the differential equations can be collected under the four titles. These are procedural understanding instead of conceptual understanding, reasoning difficulties, misconception and transition between representations. The studies in the literature showed that the rote-learning was more dominant in the course of traditional differential equations and the calculations based analytical approaches were adopted. Rasmussen (2001) stated that the students in the class of differential equation in which analytical approaches were predominantly used performed procedural learning without explaining the meaning of the relations in the process of problem- solving. However; differential equations are more a lesson based on procedural knowledge in which differentiation and integration rules are applied (Raychaudhuri, 2014). Because, when modeling a physical problem by a differential equation, solutions are mostly not expressible in closed form (Habre, 2000). Interpreting of the meaning the result along with calculating a differential equation, create an approximate solution through alternative ways in case of not being come to an exact solution are also necessary. In order to determine the strategies applied in the solution of differential equations problems having the knowledge of rules is important; however, reasoning skill is also required for the analyzing the solutions. It was determined that the students who do not have the proficiency of parametric reasoning had difficulty in the solution of differential equation problems in which dynamic systems are modeled (Allen, 2006). Many studies draw attention to the difficulties the students had in the process of modeling of a real world problem with the aid of differential equations or the interpretation of the (problem) solution modeled with the differential equation (Camacho-Machín \& Guerrero, 2015; Duvall, 2005; Wagner, Speer \& Rossa, 2007). Some reasons for the misconceptions observed in the subject of differential equations are the tendency to overgeneralize, conflict of formal and intuitional knowledge, and reversibility confusion. The application of a rule in another case which was not valid or that the equilibrium solutions were not seen as a sub-set of differential equations led to students fall into error (Rasmussen, 2001; Zandieh \& McDonald, 1999). Furthermore, that the derivative and integral operation were interpreted as the only opposite of one another causes to wrong inference in the solving of differential equations. The biggest challenges in the traditional classes are not being able to correlate between algebraic 
and graphical representation of differential equation and not being able to match between differential equation and slope.

In conclusion, the traditional courses in differential equations, which focus on various paper and pencil techniques to find exact solution for specific types of problems, are not capable for answering current needs of the higher education mathematics (Artigue, 1992; Habre, 2000; Rasmussen, 1997). In addition to this, other important outputs of course are to determine the behaviors of the differential equations not to be solved with analytical methods, to explain the relations between the concept of variable and parameter in differential equations, to interpret the change of quantity by time with the parametric reasoning and also to solve the differential equation systems using numerical or qualitative approaches. Following recommendations were given a place in order to cope with the challenges and misconceptions encountered in learning and teaching of differential equations: the presentation of teaching content with the technology-supported approaches, the use of different solution methods (analytical, qualitative and numerical) in the process of problem solving, bringing of problem situations related to real-world to teaching environment in order that the students use the differential equations in the process of modeling of dynamic systems. Culture and epistemological beliefs are also important variables in the process of formation of challenges and misconceptions. Therefore, researchers should take on the tasks about determination of different difficulties which can arise in the curriculum and pedagogy of the differential equations course. 